\title{
Ancianos y ciudad
}

\author{
ROBERTO DONOSO SALINAS \\ Universidad $N$ acional Autónomade M éxico
}

\begin{abstract}
::: RESUMEN
A partir de una reflexión que se apoya en una amplia bibliografía sobre el tema de la vejez, se desarrollan consideraciones respecto a su significación personal y social, con especial énfasis en los problemas que genera la moderna vida urbana a quiénes conforman este grupo etario. El desarrollo de una sociedad que les priva de un lugar en ella y la construcción de una ciudad que no los considera y que agudiza los problemas de esta última etapa de la vida, constituye el centro del análisis que aquí se realiza.
\end{abstract}

PALA BR AS CLAVE: ancianos, ciudad, exclusión

\section{::: ABST R ACT}

Some thoughts are made on the personal and social meaning of old age, supported on a broad bibliography on the subject, with special emphasis on problems raised by the modern urban way of life which affect this age group.T he focus of the analysis made in the paper, lies in the development of a kind of society that desplaces aged people, and in the building up of a kind of city that ignores them, thus intensifying problems in this last stage of the lifespan.

KEY W O R D S: old, age city, exclution

En su primerasalidaal mundo, Buda, entoncesSidartaencontró un hombre achacoso, desdentado todo, lleno de arrugas, canoso, encorvado, apoyado en un bastón, «antesu asombro el cochero le explicó lo que esun viejo... quédesgracia, exclamó el príncipe, quelosseresdébilese ignorantes, embriagadospor el orgullo propio de lajuventud, no vean ala vejez».

$$
\text { SIM ONe de Beauvoir, La vejez }
$$

En los años ochenta del siglo $X X$, algunos autores como $N$ un y Gouldner ha blaron de la rebelión del coro, refiriéndose a la tragedia griega en que los héroes, que se hallaban en contacto directo con los dioses, eran los únicos dignos de ser tomados en cuenta. La vida cotidiana quedaba reservada al coro, lugar subalter- 
no y sin rostro, que estaba formado por las mujeres, los niños, los viejos, los mendigos, los esclavos. «En una palabra, todos los que se quedaban en la ciudad mientras los otros partían en busca de la aventura, el poder y la gloria» (véase N un, 1981: 19; Gouldner, 1975; Lechner, 1980). ${ }^{1}$

Esperaban que los ancianos, los sin casa, los inválidos y los marginados se plantaran en medio del escenario y se dirigieran a la esfera pública exigiendo ser oídos en sus demandas, «desde su realidad diaria, sudorosa y poco mostrable.»

Aquellos autores que propiciaban y creían en la rebelión del coro, tuvieron en parte razón, y algunos grupos fueron oídos, pero los más pobres, los ancianos, los minusválidos y los niños indigentes, en especial los del tercer mundo, no han sido aún escuchados, y no lo serán mientras exista un sistema social en que el individuo vale de acuerdo a su capacidad productiva. «T ú vales cuanto producess.

Para la sociedad, los ancianos son inexistentes. Para referirse a ella se emplean palabras inocuas, «Tercera edad» 0 «Adultos en plenitud»V iejo, Anciano oVeterano, han pasado a ser palabras que están al borde de la obscenidad, hay un pudor social en nombrarlas. «Para la sociedad la vejez es un secreto vergonzoso del cual es indecente hablar» (de B eauvoir, 1983).

$\mathrm{N}$ osdamoscuenta de su existencia cuando noscausan molestias, como aquellos mendigos ancianos que nos estiran sus manos, no del todo limpias, con ropas raídas, encorvados, y nos piden en forma insistente que les demos una limosna, o bien, cuando por su lento caminar, sobre las estrechas y agujereadas veredas, obligan al apurado transeúnte a disminuir su acelerado andar, lo que hace, generalmente, lanzando fuertes increpaciones.

Los viejos salen también del anonimato cuando se les necesita ( $\mathrm{N}$ o olvidemos que en algunas localidades el $15 \%$ del electorado es anciano), pero, en general, usando las palabras de G ouldner, ellos «Son vistos pero no percibidos».

Actualmente, la mayoría de ellos, de ser una molestia para el resto de sus conciudadanos, han pasado a ser un problema.

En efecto, como consecuencia del mejoramiento de las condiciones de higiene, de nuevos medicamentos, etc., la vida humana se ha prolongado, y el mundo está siendo habitado cada vez por más veteranos. Se está ante «el peligro griss (Aguilar Derpich, 1980: 24).

Algunos ancianos que cuentan con modestos ingresos, provenientes de pensiones 0 jubilaciones, 0 que gozan de algunos beneficios en el área de salud, están empezando a ser tomados en cuenta, no por que despierten interés de por sí, sino por que otros grupos se sienten amagados, económicamente, por su sola existencia. Los ancianos ya son muchos.

Vamos a vivir en un mundo plagado de viejos ¿Q ue hacer? Son una inversión pasiva, significa, además, que en la medida que aumente el número de

\footnotetext{
${ }^{1}$ He dedicado un largo período al estudio de la teoría urbana y, tengo, además, bastantes años, por lo que la interpretación que le doy a los hechos sociales a los que me referiré, la ancianidad y la vida urbana, estarán inevitablemente influenciados por mis vivencias
} 
jubilados y pensionados, el estado no estará en condiciones de hacer frente a esta verdadera «catástrofe económica». ${ }^{7}$

Se sugieren soluciones, Giddens propone que se deje al beneficiario en libertad para elegir la fecha de su jubilación, y estima que «deberíamos contemplar a la gente mayor como un recurso y no como un problema» (Giddens, 1999: 142).

La observación que se ha hecho a este planteamiento es que los jóvenes y adultos retardarán su entrada al mercado laboral, en la medida que no se producen vacantes

En A mérica Latina al gunos proponen que se jubile a una mayor edad que en la actualidad. Probablemente se le hará la misma objeción que se le hace al planteamiento de Giddens.

M umford proponía que las ancianas se dedicaran a la costura, cuidaran niños y tejieran, y que los hombres se dedicaran al «jardín y a los servicios menores» (M umford, 1978) para que así puedan subsistir

Pero aquellos ancianos paupérrimos, que no tienen derecho alguno, ni quién se haga cargo de ellos, que mueren, de lo que A guilar (1980) llama «a enfermedad mas sutil e insidiosa de la tercera edad, el abandono y la no consideración, en las que generalmente se tiene a esa clase de personas ${ }^{11}$ siguen y seguirán siendo ignorados. A demás, es probable que esta gente que vive en la miseria, muera antes de llegar a la vejez. Pero esta actitud frente a las personas de mucha edad no es nueva, los ancianos no han sido tomados en cuenta durante la mayor parte del transcurso de la historia. Sabemos de algunos que fueron notables, $M$ iguel Angel, A ristofanes, etc, pero de la gran mayoría de ellos, no sabemos como vivían, que sentían, y como se relacionaban con el resto de la sociedad.

En general, el trato hacia los viejos, en algunas novelas, ha sido bastante despectivo. En D ostoievski, M oliere, Shakespeare, y otros autores se les describe como egoístas, tacaños, testarudos y a menudo perversos.

Es curioso que los utopistas, que soñaban con una sociedad perfecta, y que se preocupaban hasta en sus menores detalles, de como iba a ser cada edificio, en donde se alojarían sus habitantes y de las actividades cotidianas de cada cual, no

\footnotetext{
${ }^{2}$ Vale la pena recordar que en el siglo XVIII Jeremías Bentham pensaba formar una gran Sociedad Anónima, similar a la de las Indias O rientales, con cuyo capital se podría dar albergue a infantes y niños abandonados, pordioseros, minusválidos y ancianos. C reía que cualesquier persona, de cualquier edad, era capaz de generar un excedente, por mínimo que fuera, y que los dividendos que se repartiría entre los accionistas serían cuantiosos, parte de las utilidades sería en beneficio de los asilados. La arquitectura de estos asilos sería similar a los panópticos diseñadospor él. Suponía que incluso los bebés dejarían utilidades, dedicando sus deposicionesa abonos. En esta época de privatizaciones y neoliberalismo esuna idea a ser examinada ( H immelfarb Gertrude: Bentham's U topia, The N ational Charity Company» Journal of British Studies, 1970 y Bentham Jeremy $\$ 0$ utline of a Work Entitled Pauper $M$ anagement I mproved (1798) publicado en Works of Bentham, 1997)

${ }^{3} \mathrm{~A}$ los ancianos, durante muchos años, se les descontó de su salario una cantidad de dinero para que después de un tiempo pudiera jubilar. La crisis del sistema de pensiones se debe a que el Estado destinó esos recursos a otros fines, ajenos al sistema de pensiones
} 
se hayan referido al espacio que tendrían en ella los viejos. U na de las pocas excepciones fue Tomas M oro, que en su libro «U topía» los menciona y los coloca en un lugar, si bien no privilegiado, al menos de respeto por parte del resto de los «U tópicos»(M oro, 1941).12

A partir de la revolución industrial, en el siglo XIX, se empieza a hablar de lo que se ha dado en llamar la «cuestión social», se empieza a describir la vida de los desamparados, entre los que están los ancianos que habitan en las ciudades ${ }^{14}$. Las condiciones inhumanas de los asi los que los acojían, nos las narran Labreuille y D ickens. En la novela, «Le Père amable», $M$ aupassant describe a un viejo inválido que se suicida, cuando su nuera, viuda, se vuelve a casar, abandonándolo. Zolá en «aTerre» nos narra el asesinato de un anciano por sus hijos, etc. Las escenas que describen, tanto los románticos como los naturalistas, estaban reflejando una realidad social, que en lo sustancial no ha cambiado.

Estos autores, cuando escribieron sus obras, eran jóvenes, podían describir situaciones, pero ninguno estaba capacitado para captar el sentimiento de impotencia frente al mundo que sienten los ancianos. ${ }^{15}$

A ntes, las etapas de la vida estaban muy marcadas, Juventud, M adurez yVejez, pero, actualmente, el tiempo que transcurre entre el nacimiento y la muerte comprende varias etapas intermedias, que han traído modificaciones muy importantes en las relaciones entre los distintos grupos sociales y generacionales. El proceso de decadencia se presenta bajo la forma de una gradual abdicación biológica y psicológica. C on los años las personas van perdiendo el oído, la vista, y se va produciendo una lenta e imperceptible disminución de todos los sentidos. T ienen dificultades en el caminar, son torpes para asir al gún objeto, la memoria les disminuyen, y van apareciendo enfermedades propias de la edad, que los van haciendo cada vez mas dependientes de aquellos que los rodean, convirtiéndose en un carga, que los hace destestables. EI proceso de envejecimiento es lento en un principio y se va acelerando a medida que pasan los días.

Para retardar al máximo este inevitable proceso, se han inventado medica mentos y se han hecho mejoras en la higiene pública, que han permitido que muchos hayan logrado llegar a una edad muy avanzada.

Existe la idea equivocada de que la ancianidad o vejez, antiguamente, llega-

${ }^{4}$ A dam Smith, en su libro « nvestigación sobre la naturaleza y causa de la riqueza de las $\mathrm{N}$ acioness (1774) nos dice que la gente está tan miserablemente empobrecida, que se ven en la necesidad de abandonar a sus ancianos, .. y así mueren de hambre»

${ }^{5} \mathrm{C}$ yrano de Bergerac en el «O tro $\mathrm{M}$ undo» nos dice que en su sociedad ideal los ancianos rinden pleitesía a los jóvenes, y que los hijos mandan a sus padres. Los ciudadanos se habían rebelado por que la legislación se había hecho por los viejos, en su propio beneficio y en perjuicio del resto de la población, París 1645.- H e usado la edición de CO N ACU LTA, M éxiCo D.F 1992

${ }^{6} \mathrm{M}$ ark Twain constituyes una excepción, denunció la vida miserable que llevan en el siglo pasando los ancianos pobres rurales en Estados U nidos.

${ }^{7} \mathrm{H}$ ay determinadas experiencias que son inteligibles en plenitud, por aquellos que las han vivido. $\mathrm{N}$ o se trata de hacer una ciencia social intersubjetiva, como pretendía, en el siglo XIX, W ilhelm D ilthey. 
ban a más temprana edad, por lo efímera que era la vida en ese entonces. A ntes se vivía menos, pero no se llegaba a la ancianidad. M ontaigne, a los 48 años, en 1580 , nos dice que «M orir de vejez constituye una muerte excepcional, singular y extraordinaria y mucho menos natural que las otras. Extrema y extraordinaria clase de muerte es esta, y la mas alejada de nosotros, por lo que debemos considerarla lo menos posible» (M ontaigne, 1980).

$\mathrm{H}$ ay ancianos que tienen, con respecto a su futuro, un estado de ánimo positivo, siguen haciendo cosas y tienen proyectos de vida. Los hay, asimismo, decrépitos, que tiene una actitud negativa ante la vida, que carece de planes para más adelante, y que solamente desean morir. Para B obbio «el mundo de los viejos es, de forma más o menos intensa, el mundo de la memoria. La dimensión en que viven los viejos es el pasado. El tiempo futuro es demasiado breve para que preocupe por lo que sucederá» (Bobbio, 1975).

La edad de la persona en que se inicia la decadencia física varía, así, por ejemplo, Buñuel (1980) estima que la suya se inició a los 77 años, y B obbio a los 80 , pero para la mayoría, ésta se inició alrededor de los $75 .{ }^{19}$

Si el anciano no nota sus años, independientemente de lo joven que pueda sentirse, los «demás» se lo hacen sentir.

$\mathrm{N}$ orbert Elías se refiere a frases amables como «Es sorprendente como consigues mantenerte tan joven a tu edad» (Elías, 1997). ${ }^{21}$

Ernst Bloch constata que «Para la mayoría de la gente de edad es muy instructiva la experiencia de ver, por primera vez, como una jovencita se levanta para cederle el sitio. Esta cortesía tiene un efecto fatal».

Esta experiencia la hemos tenido muchos.

Es difícil, casi imposible, para una persona que no es anciana, poder sentir 0 entender lo que un viejo siente o desea.

Fuera de las autobiografías, novelas u observaciones escritas por ancianos, no hay literatura confiable respecto a los sentimientos de estos. $\mathrm{N}$ orbert Elías, a los 85 años hace notar, que para un joven o para un adulto «N o (le) resulta fácil imaginar que el propio cuerpo, tan fresco y a menudo lleno de sensaciones placenteras pueda volverse lento, cansado y torpe. No es posible imaginarlo, ni en el fondo se quiere imaginar»(Elías, 1997).

Se cita el «Tratado sobre la vejez», de Cicerón como una de las más bellas

${ }^{8} \mathrm{H}$ ay muchos, que a pesar de sus penurias físicas, mantienen susfacultades mentales intactas hasta muy avanzada edad. M as de 75 años tienen C arlos Fuentes, (77) G arcía M árquez (78), A dolfo SánchezV ásquez (90)Ernesto Sabato,(94)M ario B enedetti (85)O scar N iemayer 98, y muchos mas. que siguen produciendo obras excelentes. 0 ctavio Paz murió a los 84 y Borges a los 97, Lucios C osta a los 96, Luis Barragán a los 86, etc. Todos ellos en pleno uso de sus facultades mentales, pero físicamente muy deteriorados.

${ }^{9}$ La curiosidad por conocer la edad de los ancianos es grande, posiblemente se deba a que si la respuesta es que los años son muchos, le de al demandante una sensación de optimismo, respecto a sus posibilidades. En la Biblia, en el Génesis, 47, 7 José llevó a su padre, Jacob, a presencia del Faraón, y este se limitó a preguntarle «¿C uánto son los días de los años de tu vida», Jacob contestó, y ahí terminó la conversación con el lacónico monarca 
obras sobre el tema. El se consideraba viejo y le escribe a un octogenario interlocutor, «quiero hacerte más llevadera esta carga de la vejez que nos oprime» (1968: 40), cargas que son el debilitamiento de las fuerzas, el alejamiento de los negocios, el que no poder gozar de muchos placeres de la vida y que estar mas cerca de la muerte. Cicerón le va a encontrar un lado positivo a cada una de estas fatalidades, lo que, con toda razón, provocaba la indignación del nonagena rio Bobbio (1965)..$^{24}$

Cuando Cicerón escribió su tratado, tenía menos de sesenta años, estaba lleno de proyectos, y su discurso no nos trasmite los sentimientos y pensamientos que se tiene en la ancianidad. El discurso suena a ficticio.

Simone de Beauvoir empezó a escribir «La vejez» cuando tenía menos de 60 años y lo terminó a los 61 , es un tratado muy completo, pero no se puede trasmitir lo que no se siente. Al decir que estaba en el umbral de la vejez, ella misma lo reconoce. Posteriormente, ya anciana, a raíz de la muerte de Sartre, escribió «a ceremonia del adiós» y nos comunica sentimientos que había sido incapaz de trasmitirnos cuando escribió el libro sobre la vejez

Ernst Bloch ya anciano escribió lo siguiente: «En la ancianidad tenemos proyectos para lo que nos resta de la vida, estos proyectos, estos ensueños a futuro, los podemos hacer con respecto a nuestra propia ancianidad. A través de todos los deseo del viejo discurre un deseo, muy problemático a menudo: El deseo de la tranquilidad. U n deseo que puede ser tan atormentador, tan apasionado como el ansia anterior de distracciones. $N$ ecesita más que antes verse libre de perturbaciones.Y todo anciano desea que se le permita estar agotado por la vida, y si se halla él mismo en el torbellino del mundo, lo está de tal manera como si no se hallara en él. En una senectud no filistea, se embellece precisamente la imagen de esta tranquilidad, del campo en lugar de la ciudad, de la huída del bullicio» (1977: 23). C reo que el párrafo citado lo suscribirían la ma yoría de los viejos.

Para N orbert Elías la situación de los viejos es en la actualidad lastimosa: « oy, en la sociedad industrializada, conforme se ven mas viejos y mas débiles están mas aislados de la sociedad y del círculo de sus amistades. EI envejecimiento trae aparejada la soledad. C on excepción de la familia, nadie los visita, y en el asilo la soledad es total, se está entre desconocidos».

Los ancianos tienen entre ellos muchas cosas en común, pero en otras son muy diferentes, tienen vidas distintas y hasta opuestas. Pese a que los viejos ya no están insertos en la producción, mantienen los valores y tienen un sentido de pertenencia a la clase social de la que eran partícipes, y sus gustos estarán muy relacionados con esta clase.

Eduardo Frank, en un muy interesante libro «Vejez, A rquitectura, y Sociedad», hace una importante diferencia entre discapacitados y ancianos: «En algunos aspectos el diseño para la ancianidad no se diferencia de lo que se concibe para personas discapacitadas. El anciano está por lo general expuesto a una su-

10 «no necesito decir que considero fastidiosas estas obras apologéticas(de la vejez)» (Bobbio, 1995). 
perposición de distintos tipos de deterioro físico y psíquico. U n joven o un adulto con dificultad para caminar tiene un buen aparato perceptual para caminar... U $n$ anciano con al guna dificultad motriz, tenemosque pensar en una persona que está implicada en un debilitamiento generalizado de sus capacidadesfísicas... No hay que pensar en todo aquello que el anciano no puede hacer, hay muchas cosas que el anciano puede hacer y es recomendable que lo haga. La respuesta arquitectónica puede orientarse en el sentido de acentuar y estimular» (2003: 40).

La ciudad actual es producto de la $R$ evolución Industrial, que fue uno de los parte aguas de la historia de la humanidad. Significó la formación de una nueva sociedad, diametralmente distinta a la anterior, con nuevos valores y principios.

De la comunidad, que indica la fusión perfecta de la voluntad de aquellosque pertenecen a ella, que se identifican emotiva e instintivamente, de un modo no reflexivo, se pasó a la sociedad en que los individuos se relacionan en forma contractual, más que emocionalmente

La R evolución Industrial trajo aparejado un cambio fundamental en todas las instituciones sociales, entre ellas la de la familia, que pasó de extendida, que incluía abuelos, padre, madre, hermanos, numerosos hijos y nietos, a la familia nuclear, que se compone, generalmente, del padre, la madre y dos o tres hijos. ${ }^{28}$

La familia extendida le daba una mayor protección a todos componentes y los ancianos, con seguridad, tendrían techo donde guarecerse

La N ueva C iudad tuvo como característica su rápido crecimiento y la segregación espacial, las diferentes clases sociales vivieron separadas, en sus distintos sectores.

Es mucho lo que se ha escrito sobre la inhumanidad de la N ueva Ciudad, pero, como todo producto humano, es un fiel reflejo de la sociedad que la produjo

$\mathrm{N}$ unca terminará la discusión de si los ancianos, niños, mujeres y el coro en general, estaba mejor antes o después de la R evolución Industrial, por la simple razón que no hay documentos que nos describan la situación de estos antes de dicha R evolución (Solana, 1987)..$^{29}$

La ciudad para Park (1967) es algo más que un conglomerado de individuos y de una convivencia social. « La ciudad es mas que todo un estado de animo, un cuerpo de hábitosy tradiciones, de sentimientos y actitudes. La ciudad no es, en otras palabras solamente artefactos físicos y una construcción artificial. Esta envuelta en un proceso vital de las personas que lo habitan».

El habitante de esta gran ciudad se caracteriza por su despreocupación con respecto al prójimo y por un anhelo de una individual autonomía.

La N ueva Ciudad, que se construyó en pocos decenios, disolvió la antigua ciudad, que era al tamente integrada. Sus habitantes se radicaron de acuerdo a sus posibilidades económicas, rigiéndose por la ley de la oferta y la demanda, en donde los más favorecidos obtuvieron los mejores lugares y el resto, de acuerdo

${ }^{11}$ Existe, actualmente, en los países mas desarrollados, una tendencia a no tener hijos, por lo que la familia, en el sentido tradicional, tendería a desaparecer. 
a sus recursos, se fue ubicando en forma descendente, hasta llegar los desamparados, a las áreas menos favorecidas.

Se planificó con un criterio estrictamente económico, se trató de facilitar la circulación de mercaderías, y de los adultos con capacidad de trabajo, ya fuera que estos se transportaran en camión, automóvil, colectivo, o metro. Los viejos, los niños y los inválidos no fueron tomados en cuenta.

Según M umford (1978) «ninguna etapa de la vida ha sido tan olvidada como la senectud por la civilización y los planificadores de ciudades».

Los ancianos tienen una actitud ambivalente frente a la ciudad, los que han vivido en el campo lo añoran, pero los urbanitas, son nostálgicos de la ciudad que ellos conocieron y que ya no existe. Esta tenía dimensiones humanas. $\mathrm{N}$ o es que tengan la actitud de los prerafaelianos o de un Tolstoy, un Dostoiesky, un R ousseau o un socialista utópico, de odiosidad hacia la ciudad, simplemente les gustaría volver a vivir «su ciudad», que, según ellos, era arbolada, con aire puro, con poco ruido y con hermosa vista.

Si leemos las memorias de Sabato (1999), Bloch (1977), R amón y Cajal (1939), Buñuel (1980), C annetti (1980), etcétera, veremos que lo que mas desean esel silencio, la tranquilidad, el poder caminar por las calles con parcimonia, ver gente, sentarse en un parque a leer o a pensar, conversar en un café, la vegetación, los árboles, el césped, los paisajes, en fin, cosas sencillas que cualquier autoridad edilicia podría conceder, como de hecho ya lo han hecho muchos municipios en Europa y en algunas pocas ciudades tercermundistas. $C$ asi todos odian el automóvil, Santiago R amón y Cajal (1939), Premio N obel de medicina, en 1934 escribía: «El automóvil ha producido efectos morales inesperados en las grandes urbes. De hecho el callejero indolente y el piropo gentil a las buenas mozas ha quedado suprimido, mujeres y hombres se cuidan del ataque de estoscaballosmecánicos... pobres niños, pobres ancianos, víctimas propiciatorias del progreso y de la velocidad inútil».

Bobbio cita a un humorista: «Esos viejos... ¿Cómo se las han arreglado para pasar tantos peligros llegando sanos y salvos a edad tan tardía? C omo no acabaron bajo un automóvil, como evitaron una teja... Algunos todavía se atreven a cruzar despacito la calle ¿Es que están locos?».Y agrega Bobbio, «Estoy loco, cada vez más tambaleante, con las piernas cada vez más débiles, apoyándome en un bastón, del brazo de mi mujer, sigo cruzando la calle»

En efecto, los principales problemas cotidianos de los habitantes de la ciudad provienen, actualmente, de la cantidad de vehículos motorizados que circulan,

Es común, en las autobiografías de los ancianos, referirse a la odiosidad que sienten los jóvenes hacia con ellos. Emerson (1980) en el siglo antepasado, en

$12 \ll$ En toda la literatura los sectorespopulares aparecen poco [se está refiriendo la ciudad de M éxico en el siglo XVII y XVIII]. Toda una construcción, toda una ciudad hecha para ser vivida por diferentes estamentos, pero que apenas cabe la participación de los menos favorecidos, su peso pasa sin eco durante largosaños, o se deja notar en losmomentos de crisiso de depresión, cuando estalla algún motín o tumulto o viene el dolor en forma de calamidad atmosférica arruinando barrios extremos de muros endebles (Solana, 1987). 
sus Ensayos se queja de esa animosidad, e igual sensación tiene la mayoría de los autores que he citado.

Las causas de esta animosidad pueden ser muchas. ${ }^{40}$ B obbio hace la siguiente observación: «N o es que la vejez sea mala, sino que dura poco, Sin embargo hoy existe una retórica de la vejez, que no adopta por demás la forma por demás noble, de la defensa de la ultima edad en contra del escarnio, cuando no incluso el desprecio, que viene de la primera, sino que se representa a través de los mensajes televisivos, bajo la forma larvada de posibles nuevos consumidores. En estos mensajes no el viejo, sino que el anciano, término neutral, aparece tan campante, risueño, feliz de estar en el mundo, por que por fin puede gozar de un tónico especialmente fortificante 0 de unas vacaciones especialmente atractivas. En una sociedad que todo se compra y se vende, la vejez puede significar una mercadería más».

$\mathrm{H}$ ace al gunos años entrevisté a varias personas de distintas clases sociales, de mas de 70 años, para que me describieran la C iudad de M éxico de los años 30 del siglo XX.Todos rememoraban con ternura el barrio en que habían vivido, los juegos en la calle, las conversaciones interminables, sus hogares acogedores, abiertos a los amigos y los fugaces noviazgos entre vecinos. E vocaban con nitidez y simpatía a los ancianos, abuelos de sus amigos, que formaban una verdadera colectividad, en donde se sentían protegidos

Los que vivieron en el Centro $\mathrm{H}$ istórico, compartían estos recuerdos, a los que agregaban el movimiento y la alegría que trasmitían los muchachos universitarios, cuando la U niversidad Autónoma de M éxico estaba radicada allí. Parte importante de la vida del C entro H istórico giraba al rededor de ellos, había cafés donde se conversaba, teatro, se organizaban bailes, etcétera.

El barrio que ellos acordaban, está asociado con la idea de comunidad, en donde la gente se siente unida por sentimientos comunes, y existe entre ellos conocimiento y simpatía.

En un muy buen artículo Gilda Waldman (1988) hace un recuento de la literatura sobre la Ciudad de M éxico. Según ella,» más allá de los deliciosos recorridos de Salvador N ovo en la década de lo cuarenta, por una ciudad en rápida transformación, por la C iudad de M éxico, fue con La región mástransparente, de Carlos Fuentes, publicada en 1958, fue el que le dio a la capital el estatuto de C iudad moderna» «En los 80 los barrios cada vez mas segregados se

\footnotetext{
${ }^{13}$ Las causas del rechazo a los viejos pueden ser muchas. R ichard Sennett (1980) sostiene que esta odiosidad proviene en que se han convertido en psicológicamente inútiles para la siguiente generación «por esta razón, los terapeutas que trabajan con familias en que tres generaciones ocupan la misma casa encuentran que a los ancianos se les tolera en la medida que se comportan sumisamente». Para Eduardo Frank (2002: 8), «el privilegio esteticista de la juventud, que deriva de en sensualización alienante y publicitaria del cuerpo, relñega al viejo a la posición de lo feo, lo insoportable, la belleza moderna, al menos a partir del siglo XIX se piensa como correlato de fuerza y juventud»esta cauda la agrega el autor a la improductividad de lo senectos».
} 
convirtieron en imaginarios literarios, y en los 90 los barrios desaparecieron de la literatura mexicana».

«iLa identidad del hombre urbano podrá encontrarse actualmente en la C iudad de M éxico dispersa, violenta, hostil? Los habitantes de la megaurbe ya no se reconocen entre ellos. Las calles ya no son espacios comunales sino que de apropiación excluyente. Ingobernable, descomunal, caótica, sucia, escéptica, sobresaturada, pero también pletórica de pautas de conducta y practicas socioculturales. ¿Cómo reconstruir literariamente sus mil rostros? ¿Cómo recrear a través de las palabras la multiplicidad de ciudades que existen en ella?»

Con la especulación inmobiliaria se fueron acabando algunos barrios, las casonas y calles arboladas desaparecieron. H asta hace treinta años, la Colonia del Valle que conocí, estaba constituida por varios barrios. D e eso ya no queda nada, las casas, con sus cuidados jardines, han sido sustituidas por al tas construcciones, en la que los inquilinos que las habitan no se conocen entre ellos.- Es el aislamiento total.

Pero, si ahondamos más en que fue lo que hizo que la vida cotidiana en Ciudad de M éxico se transformara, en un plazo relativamente corto, de una ciudad apacible en una ciudad ruidosa, caótica y enervante, veremos que el factor principal, no el único, fue la introducción desmesurada del automóvil. Se reconstruyó una ciudad, olvidándose los urbanistas que existen los peatones

El poder político y económico de la industria automotriz es muy grande, y es uno de los principales ejes en torno al que gira la economía mundial.

$\mathrm{N}$ ada demuestra en forma mas clara este poder que la frase que en 1953 C harles E. Wilson, designado por el Presidente Eisenhower Secretario de Defensa, pronunció ante el Senado

«o que es bueno para los Estados U nidos de N orteamérica es bueno para la General M otors, y lo que es bueno para la General M otors, es bueno para los Estados $U$ nidos de N orteamérica». ${ }^{43}$

Todos sabemos que el automóvil ha transformado el paisaje y el entorno urbano, produce anualmente una enorme cantidad de pérdidas de vidas humanas, esta produciendo el agotamiento de los recursos naturales no renovables, y que ha contribuido al agotamiento de la capa de ozono

La opción entre invertir en una locomoción colectiva digna y eficiente, 0 invertir para que la ciudad se organice en función del automóvil, fue una decisión política.

Las ventajas que al principio ofrecía el automóvil han desaparecido, cada día se hace más lento el tráfico, para acelerarlo hay que invertir en nuevas autopistas, las que en poco tiempo masvan a estar saturadas, por que esta facilidad momentánea para transitar a inducido a la gente a comprar mas automóviles, y es un circulo de nunca acabar.

${ }^{14} \mathrm{~W}$ ilson era un fuerte accionista de la General M otors, y esta frase la dijo para defender su postulación al cargo de Secretario de D efensa. Se le pregunto si eran sus intereses compatibles con su nuevo cargo. Al parecer el Senado compartió su criterio que ya fue aprobada su designación. 
La elección ha sido o invertir en infraestructura para ser mas expedito el transporte individual o invertir en el transporte colectivo, en especial en el metro. La importancia de la industria automotriz, ha inducido a que se opte por lo primero en desmedro de las mayoría de los habitantes que no tiene automóvil.

H ace 30 años Jorge Ibargüegoitía (1976) escribió: «EI coche es la principal fuente de los problemas urbanos... Se pueden tumbar más árboles, y hacer calles mas anchas... pero llegará el momento que no habrá mas árboles que tumbar, ni espacio para hacer mas calles, ni para que por las calles corran los coches. En un futuro no muy lejano se tendrá que aceptar que se está al limite de saturación, y que hay necesidad de inhibir el uso del automóvil particular...indirectamente, fomentando un sistema adecuado y decoroso de transporte colectivo».

Se optó por el automóvil, y se inició la nunca acabada transformación de la ciudad en beneficio del automóvil. Las autoridades expropiaron terrenos para construir autopistas, ejes viales, ensancharon algunas calles, a costa de los peatones, derribaron árboles, sin preocuparse de crear parques o lugares en donde pudieran ir a recrearse los habitantes de la megaurbe.

Los ejes viales segregaron a la población, para un anciano es muy difícil alcanzar a atravesarlos en el lapso del cambio de luces, además para evitar los semáforos se crearon pasos so bre nivel, hechos para al pinistas, con una insensi bilidad total hacia los minusválidos y los ancianos.

N o es rentable gastar en los ancianos, inválidos o niños. Se pudieron haber hecho pasos bajo nivel o escalas mecánicas para hacer más llevadera la vida cotidiana de tanta gente.

Los que diseñan la ciudad son gente joven que no tiene la menor empatía con los viejos. ¿Cómo iba a tratar de entender lo que sienten esas ancianas cargadas de bolsas, subiendo con gran esfuerzo esas altas escaleras? ¿C ómo van a pensar en la humillación que infringe la ciudad a los viejos a cada instante, al atravesar las calles, al subir al camión 0 al bus. les.

$\mathrm{H}$ ay ancianos y minusválidos que su espacio vital está limitado por ejes via-

La inseguridad de la ciudad, por otra parte, hace que los espacios que siempre fueron ocupados por los viejos y los infantes hoy día están casi desiertos. La plaza pública ha sido sustituida por los $C$ entros $C$ omerciales, en donde la gente se guarece ¿Pero que tiene que ir a hacer un anciano a un centro comercial?

La gente que concurre a estos centros se siente segura, protegida, los «mall» están hechos para el consumidor, normalmente joven o adulto. El anciano no tiene espacio en ellos, sus dimensiones sobrepasan su capacidad física y son exiguos los sitios donde pueda sentarse a descansar. La lógica de estos lugares es que la gente circule para que vea el máximo de mercaderías.

El placer que puede sentir el anciano al caminar por las calles se ve opacado por las veredas descuidadas, en donde se tropieza continuamente con un pavimento disparejo, por los automóviles que se estacionan ocupando parte de ella, por las entradas que hacen a los vehículos de casas particulares en que el peatón 
camina por un chaflán con varios grados de pendiente o bien es obstaculizado en su andar por los vendedores ambulantes, que ocupan parte importante de la banqueta.

A demás de los peligros que acarrea usar al gunos espacios públicosa determinadas horas, algunas plazas, en que era un agrado para los adultos y ancianos sentarse a platicar los días sábados y domingos, han sido invadida por una cantidad de adolescentes, que beben y vociferan, y por vendedores ambulantes que aúllan y han convertido las plazas un lugares insufribles.

El caso de Coyoacán es ilustrativo de cómo los viejos, e incluso los adultos, van siendo desplazados paulatinamente de todos los espacios públicos. ${ }^{45}$

A aquellos ancianos que les gustaría ver espectáculos deportivo, ir a un estadio, con ese enorme gentío, con las dificultades que tienen los usuarios de la movilización colectiva se les hacen inalcanzables.

Ir a un cine, visitar a un familiar o un amigo, para un viejo es difícil, si el viaje tiene que hacerlo en colectivo. La altura de las gradas, la estreches de los pasillos, atestados de gente, en que cada vez que el vehículo frena abruptamente quedan algunos en el suelo, pasa a ser un sufrimiento.

La C iudad de M éxico, a la inversa de otras ciudades de la R epública, se caracteriza por el trato poco amable de los automovilistas hacia el peatón. N o respetan las señales que indican que debe dársele preferencia.Tampoco acatan la luz roja del semáforo, y si no viene otro vehículo, pasan, sin importarles el riesgo que esto significa para aquellos ingenuos transeúntes, que aun no se han dado cuenta que la luz roja es considerada por los conductores, no como obligatoria, sino que como una cortés sugerencia de no pasar. Casi nunca disminuyen la velocidad cuando doblan, lanzan el auto en contra los viandantes, que deben saltar para no ser arrollado. Los ancianos tienen que dar largos rodeos para encontrar un lugar por donde cruzar la calle con menos peligro, es más difícil que vadear un río torrentoso.- Algunos al llegar al otro lado se santiguan, y con razón. Estas infracciones, que en otras partes tienen sanciones severísimas que han servido para educar a los conductores, aquí simplemente no se consideran, sino que más bien educan a los ancianos para que definitivamente se decidan a vivir el resto de sus días en un solo lado de la calle.

Para movilizarse, todos los peatones tienen que tomar un medio de transporte colectivo. Q uisiera transcribir párrafos de dos artículos que describen en la forma como van los que se trasladan en estos medios:

El metro según R icardo G aribay (2004): «Se abren las puertas y si tiene usted agallas ¡Éntrele al tumulto! A ntes de veinte segundos entrarán a sonar las sirenillas de aviso, de un instante a otro se cerrarán las puertas, y cosa de entrar a como de

${ }^{15}$ La Plaza de C oyoacán es un ejemplo paradigmático, al igual que muchos lugares públicosno tiene servicioshigiénicos, por lo que los vendedores y todala concurrencia usa los del Sunborn's, en donde hay una larga fila de la gente que desea llegar al baño. Por otra parte, este cambio de parroquianos, ha hecho que ese sector pierda su carácter de barrio, los propietarios estén vendiendo sus bienes raíces por que sienten que es un sector muy inseguro, demás de desagardable. Se ha desvalorizado el suelo urbano en los sectores aledaños al zócalo. 
lugar, en masa, reventando, a codazos, empellones, pulidos, voces embestidas... todos han de entrar al mismo tiempo, ise cierran las puertas! Se aplastan unos contra otros y contra los vidrios los que quedan dentro...»

EI C amión, según Jorge I bargüengoitia: «Si el camión va repleto, se abre uno paso a codazos, diciendo siempre «con permiso», hasta llegar a los lugares transversales, en los que no se sabe si caben tres o cuatro. U na vez allí, dice uno «H ágame un campito» y sin esperar mas se sienta uno encima de dos pasajerOS...»

Pareciera importante hacer notar que tanto los que son discapacitados como losque no lo son, sufren las mismas molestias y tienen los mismos obstáculos en el DF; los viejos y los discapacitados no las pueden superar.

Q uisiera terminar con una muy breve referencia a la vida de los ancianos pobres en la Ciudad de M éxico. M uchos de ellos que no tienen en donde estar, en aquellos días en que llueve o hace frío, viajan en el metro hasta la noche. Llegan a unas habitaciones míseras, que las comparten con varios otros familiares, y están normalmente deficientemente alimentados. $\mathrm{N}$ o cabe duda que ser anciano y pobre suma dos desgracias que transforman lo que queda de vida en un infierno.

\section{$R$ eferencias}

A GUILAR , Derpich. (1980). R evista N exos, 35.

A LVIN , G ouldner. (1975). Sociology of every day life. En Lewis C oser (comp.), The idea of social structure. N uevaYork.

BLOCH , Ernst. (1977). El principio esperanza. M adrid:Aguilar.

Bo вBIO, N orberto. (1995). De Senectute. M adrid:Taurus.

BUÑ UEL, Luis. (1980). M i ultimo suspiro. M adrid: C ub de Lectores.

C AN N ETTI, Elias. (1980). La lengua absuelta. M adrid:A lianza Editorial.

CICER ÓN . (1968). Diálogos. M ëxico: Ediciones O asis.

De Beau vo IR, Simone. (1983). LaVejez, M éxico: Editorial H ermes.

ELÍAs, N orbert. (1997). La soledad de los moribundos M éxico: Fondo de Cultura Económica.

EM ER SO N,Waldo. (1980). Ensayos. M éxico: Porrúa.

FR AN K, Eduardo. (2003). Vejez, arquitectura y sociedad. BuenosA ires: N obuko.

Gar IBAY, R icardo. (2004).V iaje al centro de la Ciudad. En R ube G allo (comp.), M éxico, lecturas para paseantes $\mathrm{M}$ adrid:Turner Publicaciones.

GIDDEN S,Anthony. (1999). Latercera vía. M adrid:Taurus.

IBAR GUEN GO ITÍA, Jorge. (1976). Excelsior, 29 de M arzo de 1976. R eproducido en La casa de usted y otros viajes M éxico:Joaquín M ortiz, 2002.

- . (2004).V iajar en camión. En R ube Gallo (comp.), M éxico, lecturas para paseantes. $M$ adrid:Turner Publicaciones.

LECH N ER , N orbert. (1980). Vida cotidiana. Santiago: Flacso.

M ON TAIGN E, M ichel. (1980). Ensayos. M éxico: Porrua.

M O RO,Tomás. (1941). U topía. M éxico: Fondo de Cultura Económica

M U M FO R D, Lewis. (1978). Perspectivas humanas. BuenosAires: Emecé.

N U N , José. (1981).A rtículo. $R$ evista $N$ exos, 46.

PAR K, R obert. (1967). The city. C hicago:T he U niversity of C hicago Press. 
R AM ÓN Y CAJAL, R amón. (1939). El mundo visto a los 80 años. BuenosAires: Espasa Calpe.

SÁBATO, Ernesto. (1999). Antes del fin. Barcelona: Seix Barral.

SEN N ETT , R ichard. (1980). N arcisismo y cultura moderna. Barcelona: Kairós.

So LAN A, Francisco. (1987). Las voces de la Ciudad de M éxico. En LaCiudad, concepto y obra. IV Coloquio de H istoria del A rte. U niversidad A utónomade M éxico.

W AR M AN , Gilda. (1998). R eflexiones en torno a una realidad casi inexistente. La literatura de la Ciudad de M éxico en la época de los90. A cta sociológica. 